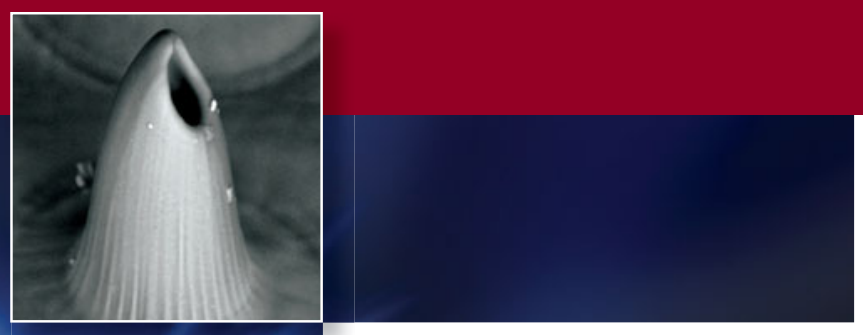

\title{
Laser micro- and nanofabrication of biomaterials
}

\author{
Roger Narayan and Peter Goering, Guest Editors
}

\begin{abstract}
Over the past half century, rapid progress has been made in laser-based medical diagnosis and treatment as well as in laser-based medical device fabrication. Lasers have unique capabilities for coating, machining, melting, polymerizing, sintering, and welding materials that are used in implantable and transdermal medical devices. In this review, academic and industrial developments involving laser processing of materials for dental, orthopedic, neural, ophthalmic, cardiovascular, and transdermal applications are described. In addition, laser processing of nanoscale materials for medical applications is discussed. Finally, challenges associated with commercialization of laser biomaterials are considered. Due to the unique capabilities provided by laser-based processes, it is anticipated that the use of laser biomaterials in implantable and transdermal medical devices will markedly increase over the coming years.
\end{abstract}

\section{Introduction}

Light amplification by stimulated emission of radiation (laser) has been used in medical applications, including manipulation of human tissues as well as processing of medical device materials, for more than 50 years. In 1960, Maiman first demonstrated the operation of what was then known as an optical maser (microwave amplification by stimulated emission of radiation); stimulated optical emission at a wavelength of $694 \mathrm{~nm}$ from chromium in corundum (ruby) was observed. ${ }^{1}$ Shortly thereafter, Javan et al. described discharge of near-infrared light from a helium-neon gaseous mixture; Johnson demonstrated continuous operation of a $\mathrm{CaWO}_{4}: \mathrm{Nd}^{3+}$ laser; Bennett et al. showed continuous oscillation from noble gas (e.g., Ne-O and Ar-O) mixtures; and Patel developed the carbon dioxide laser. ${ }^{2-5}$

Physicians and surgeons rapidly recognized the utility of lasers, since xenon arc-based photocoagulation of ophthalmic lesions had been developed in the previous decade. ${ }^{6-9}$ For example, Zaret et al. utilized a pulsed ruby laser to generate thermal injury in pigmented ocular tissues; retina and iris lesions were demonstrated in a rabbit model. ${ }^{9}$ Goldman and Rockwell noted the utility of lasers for delivering light to confined regions on the order of a few micrometers. ${ }^{10}$ They described use of the laser for microscale surgical procedures involving tissues and cells; for example, laser spectroscopy of skin was used to determine the presence of calcium. It should be noted that many early studies indicated the destructive nature of laser energy on biological tissues. ${ }^{6}$ For example, Klein et al. used a ruby laser to treat melanoma lesions in mice and noted severe lesions in tissues that were located deeper than the laser irradiation sites. ${ }^{11}$

Laser light is obtained by providing energy to a lasing medium, which results in an increase in the number of atoms in an excited state. ${ }^{6}$ When atoms fall in energy in response to photon irradiation, photons with identical energies that are in phase with the first photon are produced. Important laser properties for both laser-biological tissue interaction and laser-biomedical material interaction include beam density, exposure time, power output, and wavelength. ${ }^{6}$ Many of the medical uses of lasers do not utilize the monochromatic nature of laser energy, but instead involve localized tissue heating and cutting. ${ }^{13}$ Advantages of laser-based tissue cutting approaches include minimal tissue trauma and touch-free tissue cutting. ${ }^{6}$ For example, continuous wave lasers (e.g., carbon dioxide lasers) and optimized delivery platforms enable accurate cutting and vaporization of biological tissues; in addition, carbon dioxide lasers provide hemostasis during tissue cutting. ${ }^{6}$ Takac et al. noted that laser surgery offers better visualization and is associated with minimal postoperative swelling. ${ }^{14}$ Uses of the carbon dioxide laser include removal of tissue, sealing of small blood vessels, sealing of lymphatic vessels, and sealing of nerve endings. Applications of the argon ion laser include blood vessel coagulation for diabetic retinal damage and treatment of a variety of lesions, including telangiectasias, hemangiomas, tumors, and gastrointestinal bleeding ulcers. Neodymium-YAG (Nd doped yttrium aluminium garnet) lasers are used to treat tumors and stenotic

Roger Narayan, UNC/NCSU Joint Department of Biomedical Engineering, Raleigh, NC, USA; roger_narayan@msn.com Peter Goering, Center for Devices and Radiological Health, U.S. Food and Drug Administration, Silver Spring, MD, USA; peter.goering@fda.hhs.gov DOI: $10.1557 / \mathrm{mrs} .2011 .302$ 
(blocked) tissue. Other medical uses of Nd:YAG lasers include photocoagulation for control of bleeding as well as photoactivation of pharmacologic agents. ${ }^{6}$

Edwards et al. described medical applications of free-electron lasers, which use light emitted by accelerated electrons. Infrared light emission from these lasers may be used for human neurosurgery, including treatment of metastatic brain tumors and ophthalmic surgery. ${ }^{15-19}$ They noted that use of a free-electron laser with $6.45 \mu \mathrm{m}$ emission for tissue ablation was correlated with minimal or undetectable collateral tissue damage. This wavelength is associated with brittle fracture at the commencement of explosive vaporization, mitigating damage to collateral tissues. Femtosecond pulsed lasers are currently used for LASIK (cornea refractive surgery); in this procedure, the laser is used to ablate a portion of tissue known as a lenticule from the cornea. ${ }^{20}$ In addition, it is being considered for treatment of presbyopia (age-related vision changes) and for use in keratoplasty (cornea plastic surgery). Femtosecond laser surgeries involve two different modes. ${ }^{21}$ Processing at low irradiance involves direct multiphoton interactions and free electron-induced chemical processes; at high irradiance, thermoelastic stresses may play significant roles. Bashford described another use of lasers in medical therapy. In this approach, which is known as laser therapy, low intensity laser energy can be used to alter cellular function. This type of laser-tissue interaction may be used to treat neurological tissue, musculoskeletal tissue, and other soft tissues. ${ }^{22}$

\section{Laser processing of biomaterials}

Efforts to examine laser-material interaction for biomedical device applications have largely paralleled efforts to examine laser-tissue interaction for clinical medical applications. Some of the earliest applications of lasers for processing synthetic biomaterials involved assessment of laser welding as an alternative to conventional investment soldering. As noted by Eliades et al., the conventional mechanism for joining the brace and wing components of dental brackets involves the use of brazing alloys, which may contain small amounts of toxic cadmium. ${ }^{23}$ Gordon and Smith described laser welding of removable partial prostheses and fixed partial prostheses that were made out of a gold alloy. ${ }^{24}$ They noted that this approach provides good aesthetic properties, which is an important consideration for structures used in the front of the mouth. Yamagishi et al. demonstrated laser welding of titanium plates with a Nd:YAG laser. Using three-point bending studies, they demonstrated a correlation between processing atmosphere, laser intensity, and weld bending strength. ${ }^{25}$ Sjogren et al. noted that laser welding may be used for fusion of components in jaw boneanchored bridges, crown units, and bridge units, enabling the development of all-titanium structures. ${ }^{26}$ Bertrand et al. noted other advantages of laser welding, including the ability to join all types of metallic materials and to join metallic materials in proximity to polymeric or ceramic materials. ${ }^{27}$ In addition, the joints of laser-welded parts exhibit high strengths, which are consistent with those of the substrate material.
Amanat et al. described the use of laser welding for creating a hermetic seal involving thermoplastic polymeric materials used in medical devices. ${ }^{28}$ This technique involves melting of a polymer, which is oriented in a butt-joint or lap-joint configuration. In a lap-joint configuration, absorption of laser energy takes place at the interface between a non-absorbing (transparent) layer and an absorbing (non-transparent) layer. This approach has been demonstrated with polyetheretherketonepolyetheretherketone, poly(methyl methacrylate)-poly(methyl methacrylate), and fluorinated ethylene propylene-titanium joints. In a butt-joint configuration, the laser melts both surfaces before they are placed in contact; this approach has been demonstrated using polyethylene and polypropylene joints. Infrared light-absorbing pigments (e.g., Irodin or Lumogen) or colorless infrared light-absorbing dyes (e.g., Clearweld) may be used with laser transparent materials. Advantages of this approach include low residual stresses and localized heating; disadvantages include high capital costs and thickness limitations. Mian et al. used transmission laser welding of titanium coated glass-polyimide joints to demonstrate that optical fiber laser-welded joints provided stronger bonds than diode laserwelded joints..$^{29}$ In a recent study, Mian et al. showed that laserwelded, titanium coated, glass-polyimide microjoints lost $28 \%$ of joint strength after incubating with rat brain tissue for 10 days. ${ }^{30}$ Their work indicates that additional efforts are needed for use of polymer laser welding in medical implants.

Laser-based machining of dental implants has been considered by several investigators. For example, Minamizato described the use of a Nd:YAG laser for machining several tunnels with identical diameters in zirconia blades that are used as implant roots. ${ }^{31}$ Kasemo and Gold noted the use of laser machining for creating controlled structures, including over $1 \mu \mathrm{m}$ pits, on implant surfaces. ${ }^{32}$ They noted that a computergenerated diffractive component known as a kinoform can be used to prepare multiple parallel beams for rapidly patterning the surface of an implant. These topographical attributes may be used to alter the activity and morphology of cells at the tissue-implant interface.

Argon-ion lasers have been used to polymerize photocurable acrylate-based polymers, which are used in tooth-mimicking restorations. ${ }^{33}$ Argon-ion lasers are associated with higher energies and shorter exposure times than other curing mechanisms; however, they are not commonly used at this time due to their high cost.

Several investigators have considered the use of lasers for modifying the surfaces of implants. For example, coatings of ceramic materials, including calcium phosphate, may be deposited on the surfaces of implant materials (e.g., metallic dental implants) using pulsed laser deposition. ${ }^{34}$ In this process, laser pulses evaporate a solid target and form a vapor plume. The plume consists of evaporated and particulate materials, which subsequently condense on the surface of the substrate ${ }^{35-37}$ Films grown using pulsed laser deposition are typically $0.05-5 \mu \mathrm{m}$ in thickness. ${ }^{37}$ The parameters that determine the properties of pulsed laser deposition-grown materials 
include laser-dependent parameters (e.g., wavelength and pulse length) and target-dependent parameters (e.g., morphology, melting point, and optical reflectivity). However, macroscale particles and droplets may also attach to the coating surface. ${ }^{36}$ Droplet formation, also known as splashing, may be minimized through use of high-density targets and melt-quenched amorphous targets..$^{38}$ Irradiation of a target at high energies is associated with vapor breakdown as well as plasma formation. ${ }^{38}$ Infrared laser ablation and ultraviolet laser ablation are associated with inverse Bremsstrahlung (photon absorption by free electrons) and direct photon ionization, respectively. Advantages of pulsed laser deposition include growth of a wide variety of materials; growth of metastable phases of materials; transfer of material in a stoichiometric manner from the target to the substrate; precise control over film thickness, chemistry, and morphology; growth of composite materials through facile target manipulation; and formation of materials from ablated material-reactive gas chemical reactions. ${ }^{36,37}$ In addition, pulsed laser deposition may be used to create films out of materials with high melting points. ${ }^{38}$ It should be noted that pulsed laser deposition is a line-of-sight process that does not uniformly coat surfaces with high aspect ratios or complex geometries. ${ }^{37}$

Pulsed laser deposition is commonly used to deposit hydroxyapatite coatings on metallic substrates; these structures exhibit the mechanical properties of the metallic substrate and the biological properties of the bioactive ceramic coating. ${ }^{36}$ Hydroxyapatite is commonly considered for use in dental and orthopedic prostheses due to the fact that human bone consists of collagen fibers and nanoscale biological apatite crystals. ${ }^{36}$ Growth of high crystallinity, high purity hydroxyapatite coatings may be achieved using atmospheres containing 0.5 mbar water vapor. Hydroxyapatite coatings containing biologically relevant dopants may also be prepared using pulsed laser deposition. For example, Mihailescu et al. used krypton fluoride excimer pulsed laser deposition to deposit crystalline manganese-doped carbonated hydroxyapatite coatings on titanium surfaces. ${ }^{39}$ In vitro studies involving fibroblasts and osteoblasts indicated excellent adherence and biocompatibility of this material. Sygnatowicz et al. and Jelinek et al. created silver-doped hydroxyapatite coatings using pulsed laser deposition; Jelinek et al. showed that films with a silver concentration greater than 1.2 at.\% provided the best activity against Escherichia coli. ${ }^{40,41}$ In recent work, Mroz et al. grew magnesium-modified hydroxyapatite on nitrited Ti-6Al-4V substrates using pulsed laser deposition and showed that magnesium-doped hydroxyapatite provided better osteoblast adhesion than undoped hydroxyapatite. ${ }^{42}$

Pulsed laser deposition may also be used to grow other medically relevant coatings on metallic implant materials (e.g., cobalt-chromium alloys and titanium alloys) and on polymeric implant materials (e.g., polyurethane and polyethylene) ${ }^{43}$ For example, Evans et al. noted that diamond-like carbon, a dense amorphous hydrocarbon, that was grown from a saddle-field cold cathode ion source allowed cell growth of baby hamster kidney cells ${ }^{43}$ They also noted that diamond-like carbon exhibits corrosion resistance and wear resistance. Franks showed that diamond-like carbon grown from a saddle-field source exhibited good adhesion to titanium and polyurethane, as well as compatibility with fibroblast cells and macrophage cells. ${ }^{44}$ Narayan et al. used pulsed laser deposition involving a graphite target and a $\mathrm{KrF}$ laser to grow hydrogen-free diamond-like carbon coatings on Ti-6Al-4V alloy ${ }^{45}$ The coatings were noted to be smooth and amorphous. In subsequent work, Morrison et al. described incorporation of silver and platinum nanoparticles within diamond-like carbon matrices by means of a multicomponent target pulsed laser deposition approach. ${ }^{46}$ These materials exhibited passive behavior at open-circuit potentials and low corrosion rates in phosphate-buffered saline electrolyte. In an in vitro study, the metal-doped films were shown to exhibit antimicrobial activity against Staphylococcus bacteria.

A technique that is similar to pulsed laser deposition, known as matrix-assisted pulsed-laser evaporation (MAPLE), has been used to deposit organic coatings for implantable medical device applications. ${ }^{47}$ In this technique, an ultraviolet excimer (e.g., a krypton fluoride laser or an argon fluoride laser) is used for ablation of a frozen solution containing whole molecules of the organic material in a volatile solvent. Due to high absorption of laser energy by the solvent, ablation of a thin layer of the target material occurs. Due to their low sticking coefficients, the solvent molecules do not deposit on the substrate. Instead, the organic molecules deposit on the substrate and form a coating. This approach provides excellent control over film roughness and film thickness. For example, Bubb et al. showed that polyethylene glycol coatings deposited using MAPLE exhibited the same chemical structure as the starting material. ${ }^{48}$ In subsequent work, Cristescu et al. created films containing poly(1,3-bis(p-carboxyphenoxy propane)-co-sebacic anhydride) and gentamicin using MAPLE. ${ }^{49}$ In vitro studies confirmed the activity of the gentamicin-doped films against Escherichia coli and Staphylococcus aureus. These coatings may be used to prevent infection of medical implants and indwelling catheters. Malone et al. described use of MAPLE for depositing polymer-drug coatings on the surfaces of balloon catheters and stents that are used for angioplasty of the coronary arteries. ${ }^{50}$

Efforts involving laser-based melting of biomaterials have also been evaluated. For example, Kurella and Dahotre reviewed the use of laser surface engineering for melting, heating, or ablating the surfaces of implant materials..$^{35}$ They noted that one benefit of laser surface engineering over competing techniques is that laser-based techniques can be rapidly performed; in addition, these techniques do not require a vacuum or use of organic solvents. Carbon dioxide, excimer, and Nd:YAG laser micromachining may be used to create surface textures with micrometer-scale or sub-micrometer-scale features. ${ }^{35}$ Carbon dioxide lasers may be used for texturing of metallic and ceramic (e.g., zirconia) surfaces. Gyorgy et al. demonstrated melting of titanium without vaporization using a Nd:YAG laser; this process was used to form microscale patterns such as wave-like structures. ${ }^{51}$ Excimer lasers are particularly useful for micromachining of polymeric materials due to the low degree of thermal effects. 
Paital and Dahotre described use of direct laser melting for creating calcium phosphate coatings; this processing involves (a) mixing calcium phosphate powder with a water-based organic solvent, (b) spraying the resulting solution with a spray gun, (c) drying in air, and (d) scanning the treated surface with a laser beam. ${ }^{52}$ Both continuous wave and pulsed lasers have been used with this laser melting approach. Recent efforts by Engelman et al. have sought to incorporate laser-based interference patterning with laser melting in order to obtain textured surfaces and other microscale features. ${ }^{53}$

\section{Laser-based prototyping methods}

Laser-based rapid prototyping methods, including selective laser melting, selective laser sintering, and laser-engineered net shaping, have been used for additive manufacturing of a variety of dental and orthopedic implants from computeraided design data. Murr et al. as well as Vandenbroucke and Kruth have described the use of selective laser melting to create metallic structures for biomedical applications. ${ }^{54,55}$ For example, Vandenbroucke and Kruth described use of selective laser melting for implant manufacturing. ${ }^{56}$ This technique involves selective melting of vertically stacked powder layers using a diode-pumped $\mathrm{Nd}$ :YAG laser in order to create three-dimensional structures with an accuracy below $40 \mu \mathrm{m}$. A Ti-6Al-4V alloy framework to support tooth implants for use in an edentulous (toothless) patient was demonstrated using this approach. Advantages of selective laser melting are that it provides accurate implant-framework fitting, and it requires less labor than conventional methods. Murr et al. examined processing of the Ti-6Al-4V alloy using selective laser melting; this approach may be used to create customized implants from threedimensional imaging data (e.g., computed tomography data). ${ }^{54}$ They fabricated structures that were comparable in shape to implant precursors; these structures exhibited mechanical properties similar to or superior to those of cast or wrought Ti-6Al-4V alloy. Hagedorn et al. recently considered the use of selective laser melting for creating structures with complex shapes and nearly $100 \%$ densities out of alumina-zirconia powder. By pre-heating to $1600^{\circ} \mathrm{C}$, crack formation due to thermal stresses was avoided. ${ }^{57} \mathrm{~A}$ dental restoration bridge was created using this approach. A desktop device for selective laser melting of dental prostheses (e.g., crowns and bridges) is commercially available. ${ }^{58}$ This device, known as the Realizer, provides cobaltchromium and gold-based alloy structures with $\sim 30 \mu \mathrm{m}$ layer thicknesses. In another study, Shishkovsky et al. described use of selective laser sintering/melting to fabricate implants for craniofacial applications out of Nitinol, a superelastic/ shape-memory material, or titanium. ${ }^{59}$ A Nitinol structure with a tooth-like shape and porous morphology was demonstrated using this approach. An in vivo study involving laboratory rats showed an absence of corrosion or adverse tissue response. Rimell and Marquis considered use of selective laser sintering for processing ultrahigh molecular weight polyethylene. However, the laser-processed material exhibited several undesirable attributes, including shrinkage, porosity, and chemical degradation (e.g., cross-linking, chain scission, and oxidation). ${ }^{60}$ Palcic et al. and Ram et al. described the use of laser-engineering net shaping for creating implants out of titanium alloy and cobalt-chromium-molybdenum alloy, respectively. ${ }^{61,62}$

\section{Ultrafast laser pulses}

Nayak and Gupta described use of ultrafast laser pulses for creating self-organized structures that contain conical microscale and nanoscale features out of aluminum, copper, titanium, and stainless steel; these structures may be used to obtain enhanced cell proliferation. ${ }^{63}$ In addition, they used a direct laser process to create arrays of nano/micropores in titanium foil. In subsequent work, Bush et al. used a single-step titanium:sapphire laser-based process to create textured, hierarchical features on titanium sheets. ${ }^{64}$ Micrometer scale peaks and troughs as well as sub-micrometer scale and nanometer scale features were created using this approach. The hydrophilic nature of the treated surface was retained over time; no measurable contact angle was noted for the laser-treated material after several weeks in a normal atmosphere. During in vitro studies, attachment of bone marrow stromal cells, including cellular bridge formation, as well as proliferation of human mesenchymal stem cells at early time points, were noted. A mixed cell population from human bone marrow was grown on these materials. Differentiation of the osteoprogenitor cells, as evidenced by alkaline phosphatase and osteocalcin gene expression, was associated with osteogenic activity (i.e., bone formation or bone repair).

\section{Neural implants}

Laser processing of biomaterials for neural implants has also been considered. For example, Rosen et al. described laser drilling of holes in silicon chips for capturing nerve cell fibers, which are known as axons; potential applications of these devices include use as a prosthesis-nerve interface and as a nerve graft. ${ }^{65}$ During in vivo testing, these nerves remained viable in two primates for more than three months as well as in four rats for between six months and one year. These devices have potential use in nerve repair devices, nerve grafts, and prosthesis-nerve interfaces. Dupas-Bruzek et al. used a KrF excimer laser and a frequency-quadrupled $\mathrm{Nd}$ :YAG laser for surface modification of poly(dimethylsiloxane) (PDMS) ${ }^{66}$ They demonstrated that the laser processing conditions (e.g., the pulse duration) and the laser type determine the ablation depth, the chemical composition, and the surface morphology. An autocatalytic platinum bath was subsequently used for selective platinum metallization of the laser-irradiated contacts and tracks. These materials have potential use in electrodes for stimulation of the optic nerve in visually impaired individuals. ${ }^{67}$ Lacour et al. described fabrication of stretchable electronics on elastomeric substrates for use in medical prosthesis-tissue interfaces that are mechanically and electrically matched. ${ }^{68}$ They deposited an array of $200 \mu \mathrm{m} \times 200 \mu \mathrm{m}$ diamond-like carbon islands on a masked PDMS substrate using pulsed laser deposition. They subjected the substrate to uniaxial stretching; at a strain of $25 \%$, the diamond-like carbon islands stayed attached to the 
PDMS substrate and strained up to 5\%. In addition, a row of 11 diamond-like carbon islands that had been connected with gold stretchable metallization was shown to retain end-to-end electrical conduction when subjected to $20 \%$ tensile strain.

\section{Ophthalmic implants}

Lasers may be used for in situ manipulation of biomaterials during ophthalmic surgery. For example, Chirila et al. noted that acrylic polymers may undergo undesirable degradation processes, including toxic monomer release, after interaction with short pulse lasers. ${ }^{69}$ They discussed the effect of pulsed laser irradiation on poly(methylmethacrylate) (PMMA) and poly(2hydroxyethyl methacrylate) (PHEMA), which are used in intraocular lens implants. In an experimental study, Chirilia et al. showed that Q-switched Nd:YAG laser-irradiated PMMA did not exhibit a detectable increase in methyl methacrylate monomer content. ${ }^{70}$ In addition, laser interaction with PHEMA did not result in residual 2-hydroxyethyl methacrylate. In subsequent work, Newland et al. exposed several polymers used in intraocular lenses, including acrylic, silicone, and PMMA, to Nd:YAG laser energy. ${ }^{71}$ Silicone was shown to exhibit the lowest threshold for laser-induced damage; higher laser damage thresholds were observed for acrylic and PMMA. Thompson et al. noted that laser welding may be used during an ophthalmic surgery known as synthetic epikeratoplasty for attaching a synthetic lenticule to the cornea in order to correct refractive errors. ${ }^{72}$

\section{Laser fabrication of cardiovascular devices}

Laser fabrication of cardiovascular devices, particularly endovascular stents for treatment of coronary artery disease, has become a focus of academic and industrial efforts over the past decade. For example, manufacturing of endovascular stents made from Nitinol involves laser machining of tubes or sheets that are subsequently rolled into tubes. ${ }^{73}$ Shabalovskaya et al. and Cui et al. noted that laser surface melting may be used to refine and homogenize the surface microstructure of Nitinol..$^{74,75}$ The laser-melted surfaces exhibited significantly improved corrosion resistance, as evidenced by a decrease in nickel release and an increase in breakdown potential. Higher amounts of titanium and titanium oxide were noted on the laser surface-melted material than on the mechanically polished material; this composition was associated with a reduction of nickel ion release and an enhancement of corrosion resistance. Kathuria described machining a $316 \mathrm{~L}$ stainless steel hollow tube using a short pulse Nd-YAG laser in order to obtain a cardiovascular stent; small-scale features, including slits with widths of $0.05-0.1 \mathrm{~mm}$ and pitch values better than $0.2 \mathrm{~mm}$, were prepared using this approach. ${ }^{76}$ This work suggests that a reduction in the heat affected zone, which is associated with embrittlement, may be obtained with higher pulse repetition rates and shorter pulses. Sudheer et al. used a pulsed Nd:YAG laser to machine cobalt-chromium tubes for cardiovascular stents. ${ }^{77}$ An acousto-optic device was used to obtain a focus diameter on the order of $35 \mu \mathrm{m}$ and minimal thermally induced deformation. In a subsequent study, a similar approach was used to machine 316 LWM stainless steel tubes. ${ }^{78}$ Extremely fine holes were prepared using this system and a piercing approach; in addition, a reduction in the heat affected zone was observed.

Laser processing of polymeric stents has also been considered. For example, Lootz et al. considered machining of polyhydroxybutyrate stents with a carbon dioxide laser. ${ }^{79}$ In particular, they examined embrittlement of these stents after carbon dioxide laser machining. Changes in molecular weight and changes in plasticizer (triethylcitrate) content were noted, which were correlated with the distance from the laser cut site. In an in vitro study, L929 mouse fibroblasts were shown to preferentially grow on the laser-machined material. Grabow et al. used a carbon dioxide laser to machine pure poly(L-lactide) (PLLA) as well as PLLA containing various amounts of triethylcitrate. ${ }^{80}$ The laser affected cut edge contained relatively amorphous material; $0-15 \%$ crystallinity was observed in this region. In subsequent work, Grabow et al. created a balloon-expandable slotted tube stent out of a polymer blend material containing PLLA and poly(4-hydroxybutyrate). ${ }^{81}$ Balloon-expandable slotted tube stents were fabricated from polymer tubes using a carbon dioxide laser plotter. Scanning electron microscopy revealed that the laser cut material contained melted strut edges; these features are associated with reduced crack initiation (Figure 1).

Recent efforts have involved use of ultrafast lasers for stent processing. For example, Mielke et al. used an ultrafast laser to machine Nitinol, polytetrafluoroethylene, and a biodegradable polymer stent material; no observable heat affected zone was noted for the laser-machined Nitinol stent. ${ }^{82}$ Muhammad et al. described a wet cutting approach for improving the properties of laser-processed stent materials. ${ }^{83}$ They demonstrated wet cutting of $316 \mathrm{~L}$ stainless steel tubes using a pulsed fiber laser while water flowed within the tubes. This wet cutting process was associated with an absence of back wall damage, a smaller heat affected zone, less dross, and lower surface roughness.

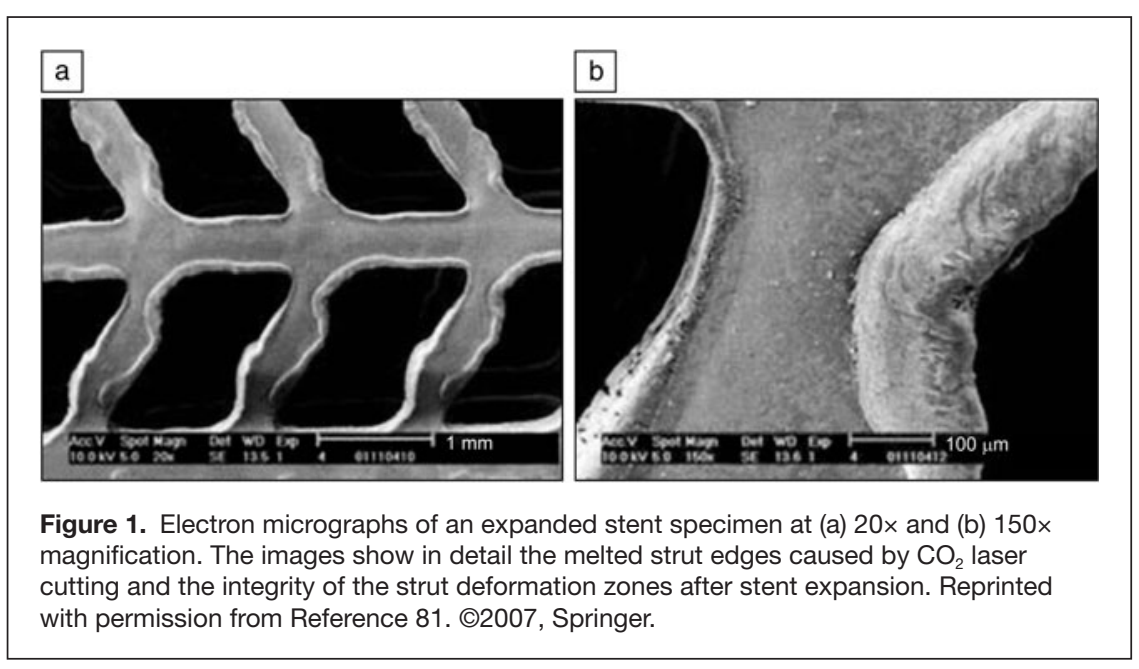



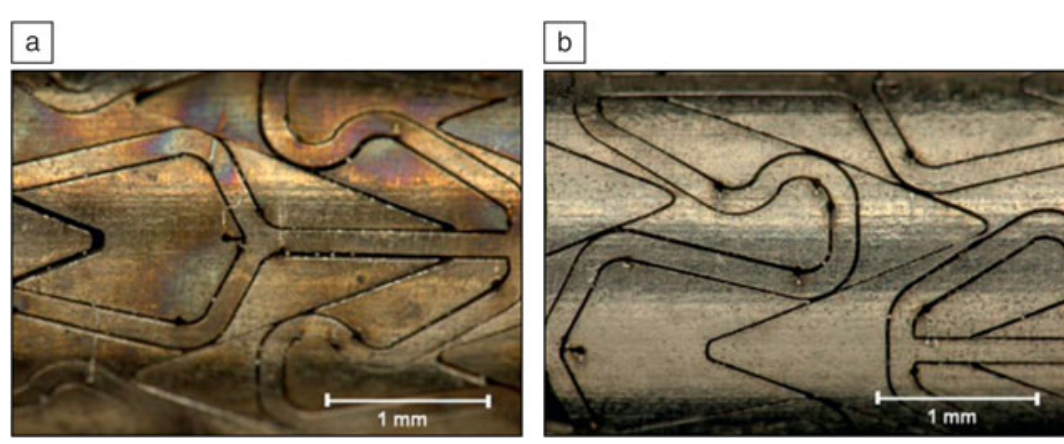

Figure 2. Thermal discoloration in stent cutting before removing the excess material: (a) dry cutting and (b) wet cutting. Reprinted with permission from Reference 83. @2010, Elsevier.

of commercial materials. Popovici et al. used carbon dioxide laser pyrolysis to create iron/iron oxide core-shell nanoparticles from $\mathrm{Fe}(\mathrm{CO})_{5}$ vapor within a $\mathrm{C}_{2} \mathrm{H}_{4}$ carrier. ${ }^{88}$ The mean sizes of the particles were estimated to be $15 \mathrm{~nm}$. $\mathrm{X}$-ray diffraction indicated that the material had a spinel structure. Nanoparticles dispersed in a light hydrocarbon, petroleum were shown to be well separated; small aggregates or single particles were noted. Large particle aggregates were trapped with a toluene bubbler that was located in front of the collection filter. These materials may find use as contrast agents for magnetic resonance imaging of patients. Asahi et al. described laser ablation of organic microcrystalline powders in

As shown in Figure 2, dry stent cutting was associated with thermal discoloration indicative of embrittlement; on the other hand, water cutting was not associated with these changes. It should be noted that laser-machined stents are currently in clinical use; for example, laser-machined 316 L stainless steel balloonexpandable stents containing sirolimus have been used for clinical treatment of patients. ${ }^{84}$ Another commercially available stent is made out of WE43 absorbable magnesium alloy; this device, which contains noose-shaped and unbowed cross-link geometries, is laser sculptured from a single tube of material. ${ }^{85}$

\section{Laser-fabricated nanoscale materials}

Laser-fabricated nanoscale materials have been considered for use in medical devices and other medical applications. For example, Tavakoli et al. reviewed the use of laser pyrolysis of organometallic precursors for biomaterial applications. ${ }^{86}$ This technique relies on interactions between gaseous species and photons from a carbon dioxide laser. They noted that this approach may be used to prepare a variety of 2-20 nm particles, including cementite-containing iron-carbon nanostructures, $\alpha$-iron oxide nanoparticles, and $\gamma$-iron oxide nanoparticles, with controllable size distributions. This technique has not been translated to commercial use, since it is burdened by high energy consumption as well as low production rates. Veintemillas-Verdaguer et al. performed continuous laser pyrolysis of $\mathrm{Fe}(\mathrm{CO})_{5}$ vapor in order to create $5 \mathrm{~nm} \gamma-\mathrm{Fe}_{2} \mathrm{O}_{3}$ nanoparticles. ${ }^{87}$ These particles were dispersed in a dextran-containing strong alkaline solution in order to create magnetic dispersions for use in magnetic resonance imaging. Particle-aggregates were formed in these dispersions that exhibited a hydrodynamic diameter of $42 \mathrm{~nm}$ determined using photon correlation spectroscopy and a diameter of $25 \mathrm{~nm}$ determined using transmission electron microscopy; as noted by Veintemillas-Verdaguer et al., a particle size smaller than $200 \mathrm{~nm}$ is desirable from a toxicity perspective. During an in vivo study, the dispersions were intravenously administered to mice, and a blood clearance half-life of $7+/-1$ minutes was observed. In addition, enhancement of magnetic resonance image contrast after administration of the dispersion was noted. The biokinetic profiles and ${ }^{1} \mathrm{H}$ NMR relaxation times of the laser pyrolysis-produced dispersions were similar to those water to form nanocolloids ${ }^{89}$ Processing of various nanoparticles in this manner was demonstrated, including the anticancer drug 7-ethyl-10-hydroxycamptothencin and the fullerene C60, which is being considered for use in photodynamic therapy.

Singh recently reviewed the use of zinc oxide nanostructures for biomedical applications, noting that zinc oxide is useful for biomedical sensors (e.g., glucose oxidase-based sensors) since it exhibits rapid electron transfer behavior..$^{90}$ In addition, it can be used for modifying and immobilizing biological molecules. Okada et al. fabricated $\sim 120 \mathrm{~nm} \mathrm{ZnO}$ nanorods using a catalystfree nanoparticle assisted pulsed laser deposition approach. ${ }^{91}$ Optical pumping of the $\mathrm{ZnO}$ nanorods at $388 \mathrm{~nm}$ was used to obtain stimulated emission. In subsequent work, Okada et al. used laser ablation in a high-temperature argon background gas to prepare $\mathrm{ZnO}$ nanorod structures with unusual geometries, including nanowire pig-tailed $\mathrm{ZnO}$ nanorods and $\mathrm{ZnO}$ nanocones. ${ }^{92}$ More recently, Okada and Suehiro used nanoparticleassisted deposition to create $\mathrm{ZnO}$ nanowires with lengths up to $5 \mu \mathrm{m}$ and diameters between $50 \mathrm{~nm}$ and $150 \mathrm{~nm}$; the photoluminescent behavior of these materials was confirmed by excitation with a Nd:YAG laser. ${ }^{93}$ In addition, stimulated emission under optical pumping was demonstrated. Potential applications of nanostructured zinc oxide include use in ethanol, hydrogen, oxygen, and $\mathrm{pH}$ sensors. ${ }^{93}$

\section{Two photon polymerization}

As previously noted, ultrafast lasers provide unique capabilities for processing biomaterials. Itoh et al. noted that ultrafast lasers can provide extremely high energy densities within small volumes, leading to complex, nonlinear, and localized interactions that are referred to as nonlinear focal-point optics. ${ }^{94} \mathrm{At}$ lower energies, nonlinear focal-point optics is used in optical microscopy. For example, it can provide three-dimensional imaging capabilities without laser scanning optics. At higher energies, nonlinear focal-point optics enable manipulation of cells, intracellular particles, and intracellular organelles. At even higher energies, nonlinear focal-point optics are utilized for selective photopolymerization or machining of material. Two photon polymerization, a liquid-based rapid prototyping technology based on this approach, has been utilized for the 
fabrication of small-scale three-dimensional medical devices out of several types of photosensitive materials, including epoxy oligomer-containing commercial photoresist (SU-8), acrylate-based polymers, organically modified ceramic materials, titanium-containing sol gel composite materials, and zirconium oxide-based hybrid materials. ${ }^{95-99}$ Nearly simultaneous absorption of two $800 \mathrm{~nm}$ photons from a femtosecond titanium:sapphire laser by the photoinitiator induces an electronic excitation analogous to excitation by the ultraviolet light region of the electromagnetic spectrum. ${ }^{100,101}$ Photoinitiator molecules that are sensitive to $390 \mathrm{~nm}$ radiation are therefore commonly used for two photon polymerization. Chemical reactions between photoinitiator molecules and monomers lead to polymerization of a volume of material, which is known as a voxel. Layer-by-layer processing of three-dimensional structures is commonly achieved by moving the laser focus on a twodimensional scanning path; beam translation is performed along the $z$-axis. Soft lithography methods, such as replica molding, microtransfer molding, microcontact molding, and microcontact printing, may be used for high fidelity replication of two photon polymerization-fabricated structures. ${ }^{102-104}$

Small-scale medical implants and prostheses have been created using two photon polymerization. For example, Ovsianikov et al. prepared ossicular replacement prostheses, which serve as replacements for the middle ear bones, out of organically modified ceramic material using two photon polymerization. ${ }^{105}$ The head of the two photon polymerization-fabricated prosthesis contained five conical structures, which may serve to enhance cell attachment and minimize prosthesis migration. The prosthesis was implanted and subsequently removed from an implantation site in a frozen human head without fracturing. Schizas et al. utilized two photon polymerization to create micro-valves out of a zirconium-containing sol gel. ${ }^{106}$ The two photon polymerization-fabricated structure exhibited a check valve design and contained a mobile piston rod within a valve body. The features in this structure correspond with the anatomic features of small veins that prevent blood flow reversal. Scanning electron microscopy data indicated that the valve components were successfully fabricated; in addition, mechanical actuation of the piston rod with a needle was demonstrated.

\section{Microneedle fabrication}

Two photon polymerization and other laser processes have been used to prepare transdermal medical devices known as microneedles. Microneedles are small-scale hypodermic needle-, thorn-, or lancet-shaped structures exhibiting one dimension below $500 \mu \mathrm{m}$ in length. These devices are used to create pores in the $15 \mu \mathrm{m}$ thick stratum corneum layer of the skin, enabling transdermal delivery of pharmacologic agents and vaccines. Microneedles with complex shapes, including in-plane hollow microneedles, out-of-plane hollow microneedles, and mosquito fascicle-shaped microneedles, have been created out of organically modified ceramic materials using two photon polymerization. ${ }^{107-109}$ These studies showed that microneedle design may be rapidly tailored for specific medical applications using two photon polymerization. In another study, hollow microneedles with 500-700 $\mu \mathrm{m}$ heights were created out of an acrylate-based polymer using two photon polymerization. ${ }^{110}$ Figure 3 shows scanning electron microscopy images of an individual microneedle within a $3 \times 3$ microneedle array. The base diameter and length of the microneedles in the array were $212+/-3 \mu \mathrm{m}$ and $508+/-33 \mu \mathrm{m}$, respectively. It should be noted that both the microneedle and the microneedle base shown in these images were fabricated using two photon polymerization. These devices were used to create pores in the stratum corneum layer of cadaveric porcine skin that allowed delivery of carboxyl quantum dots to the deep epidermis and the dermis within 15 minutes. On the other hand, topically applied carboxyl quantum dots remained on the topmost $50 \mu \mathrm{m}$ of the skin and demonstrated poor penetration. In recent work,

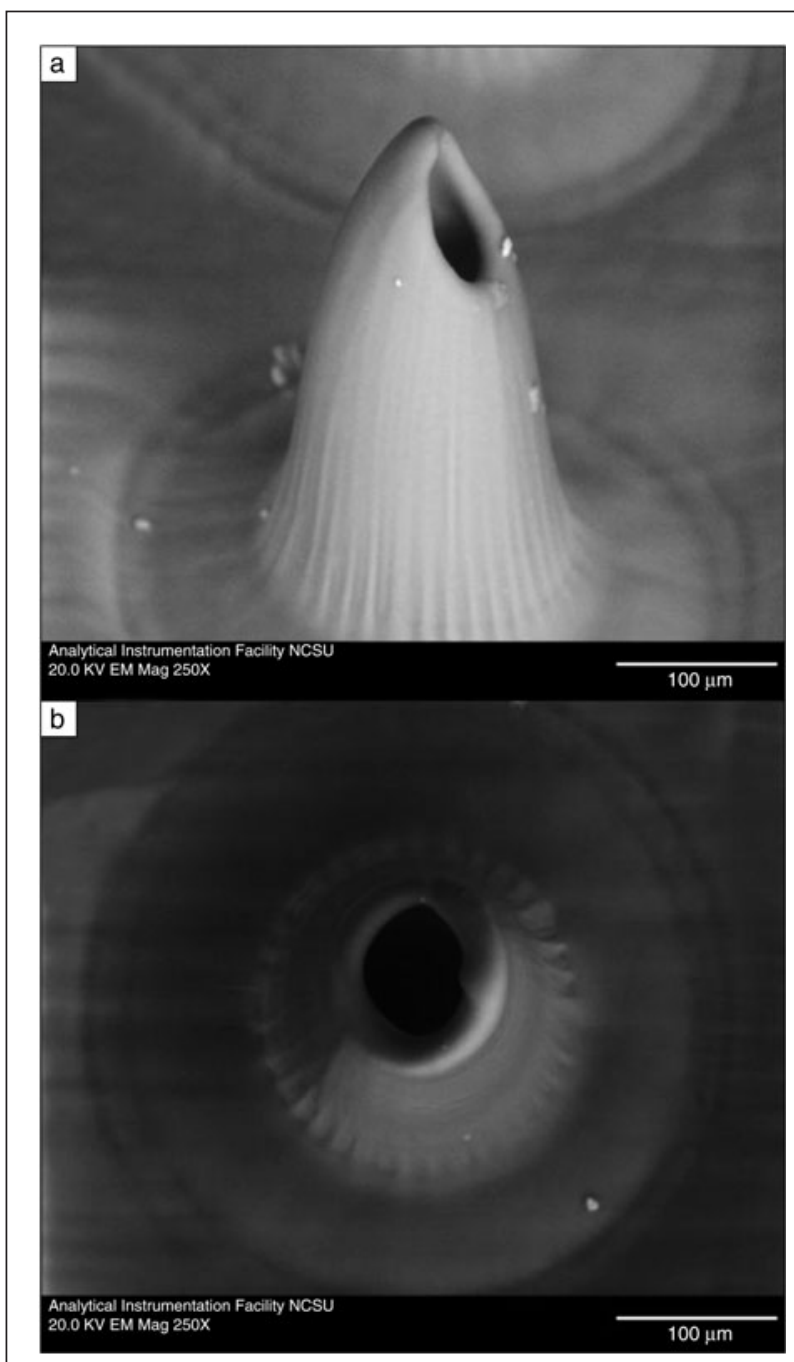

Figure 3. Scanning electron microscopy images of an acrylatebased polymer hollow microneedle produced using two photon polymerization. (a) Image of an individual microneedle obtained at a 45 degree tilt. (b) Image of an individual microneedle obtained at a 0 degree tilt. Dimensions are shown as average $+/-$ standard deviation. Reprinted with permission from Reference 110. (02011, Royal Society of Chemistry. 
a two-photon polymerization process involving multiple foci was used to prepare an array of microneedles out of organically modified ceramic material. ${ }^{111}$ Using this approach, multiple beams were obtained from a single laser with a computerprepared hologram. A structure containing 36 microneedles was created using a three-by-three array in which each unit contained four microneedles. This multiple foci approach provides more rapid processing rates and may facilitate translation of two photon polymerization technology to commercial use.

Other laser-based approaches have been used to prepare microneedles. For example, Martanto et al. created $1 \mathrm{~mm}$ long solid microneedle arrays containing 105 microneedles from SS304 stainless steel sheets by ablating the trace of the microneedle geometry and manually bending the microneedles out of the plane of the sheet; electropolishing was subsequently used to reduce microneedle thickness. ${ }^{112}$ In subsequent work, Gill and Prausnitz used a similar approach to create in-plane and out-ofplane microneedle arrays. ${ }^{113}$ Davis et al. created $500 \mu \mathrm{m}$ long hollow metal microneedles from polyethylene terephthalate molds; these molds contained holes that were drilled using a $248 \mathrm{~nm}$ ultraviolet laser. ${ }^{114}$ Molds containing straight-walled holes were used to create cylindrical tubes; molds containing tapered holes were used to create conical microneedles. The molds were subsequently coated with nickel using an electroplating process that used direct-current sputtered titaniumcopper-titanium as a seed layer. The nickel microneedle arrays were removed from the molds using a concentrated sodium hydroxide solution. Bodhale et al. described use of micro-hot embossing and ultraviolet excimer laser processing to create arrays of 25 hollow polymer microneedles. ${ }^{15}$ Pulsed laser deposition has also been used to modify microneedle surfaces. For example, krypton fluoride excimer pulsed laser deposition was used to deposit silver coatings on solid organically modified ceramic microneedles, which were created using a two photon polymerization-micromolding approach. ${ }^{116}$ In a disk diffusion study, these coated microneedles were shown to inhibit Staphylococcus aureus growth. In work by Choi et al., krypton fluoride excimer laser ablation was used to pattern a dc sputtered titanium/copper seed layer on a PMMA microneedle array. The microneedle array was then coated with nickel using an electrodeposition approach. ${ }^{117}$ Electroporation (electric fieldinduced plasma membrane permeabilization) of prostate cancer cells and red blood cells using this metal-coated microneedle array was demonstrated. Windmiller et al. used pulsed laser deposition to grow a platinum thin film on a solid microneedle array, which was prepared out of an acrylate-based polymer using a visible light dynamic mask micro-stereolithography system. ${ }^{118}$ This film served as a working electrode in a twocomponent microneedle array, which included solid and hollow microneedles. The array contained microscale cavities that held glucose oxidase or glutamate oxidase within a poly(ophenylenediamine) film. Rapid, selective, sensitive, and stable detection of glucose and glutamate was demonstrated using these amperometric sensors. For example, the microneedlebased sensor provided detection of glutamate over the entire pathophysiological range down to the ten $\mu \mathrm{M}$ level in undiluted human serum. ${ }^{118}$ Donnelly et al. used a $355 \mathrm{~nm}$ laser micromachining system for drilling patterns in a PDMS sheet, which was subsequently used to create solid microneedles out of several biodegradable polymers. ${ }^{119}$ In a similar approach, a programmable carbon dioxide laser writer was used to create a PDMS mold, which was subsequently used to create agarose and carboxylmethylcellulose microneedle arrays. ${ }^{120}$

\section{In this issue}

In this issue, several recent efforts involving laser processing of biomaterials with microscale and nanoscale features are described. For example, Chua et al. describe modeling and processing of functionally graded scaffolds for bone tissue engineering that take mechanical properties and anatomic geometries into account. The rapid prototyping technique known as selective laser sintering (SLS) was used to create a femur model with functionally graded attributes. Duan and Wang review the application of SLS to prepare materials for use in other medically relevant structures, including drug delivery vehicles and tissue engineering scaffolds. Guillemot et al. discuss the use of laser-assisted bioprinting for creating microscale patterns of cells (e.g., human osteoprogenitor cells) and tissue-relevant biomaterials (e.g., alginate and hydroxyapatite). Hsieh et al. review materials with microscale and nanoscale features for tissue engineering applications, including microgels structured using two-photon laser scanning photolithography. These structures contain features that facilitate intercellular interactions, cell migration, and cell self-assembly. Prodanov et al. discuss the use of laser surface engineering to create materials with microscale and nanoscale features; assessment of laser-textured materials using biological studies, including in vitro, pre-clinical, and clinical studies, is described. Riggs et al. review the use of a laser direct-write method for rapid prototyping of biomaterials (e.g., proteins and growth factors) as well as cells (e.g., pluripotent stem cells and mammalian cells). Sugioka and Cheng used a combination of femtosecond laser direct writing and wet chemical etching to create optical and microfluidic glass devices for biological analysis. Devices prepared using this approach may be used for sensing of biologically relevant molecules in fluids as well as detection of microorganisms. Zhang and Chen used two photon polymerization to create two-dimensional topographical patterns and scaffolds with sub-micrometer features out of a hydrogel material, poly(ethylene glycol). In addition, they used nanoimprinting to transfer patterns from laser-fabricated molds to hydrogels in a parallel manner.

\section{Conclusions}

As shown in the previous examples, lasers have been used over the past half century to create medical and dental implants with longer lifetimes and better functionalities than conventional counterparts. Important considerations in the development of laser biomaterials include expanding the number of precursor materials, particularly biodegradable materials. Additional 
efforts are needed to optimize laser-based processes so that materials with optimal biological, chemical, and mechanical properties for a given application are obtained. In addition, hybrid processes that take advantage of two or more laserbased processes may play important roles. Mitigation and minimization of undesirable features associated with laserbased processing (e.g., heat affected zones) must be considered. Continuing efforts to develop improved laser sources will no doubt extend the already expansive frontiers of laser biomaterials. For example, the development of low-cost femtosecond lasers (e.g., low cost oscillators or high power lasers that obviate the use of oscillators) would facilitate industrial translation of femtosecond laser-based processing, including two photon polymerization and nanomachining. Semiconductor lasers, which do not require alignment, controlled vibration, or controlled humidity, would also facilitate laser biomaterials research efforts..$^{20}$ Finally, commercialization-related challenges must be taken into account; for example, laser-based fabrication must be cost competitive with conventional (e.g., machiningbased) approaches.

The mention of commercial products, their sources, or their use in connection with material reported herein is not to be construed as either an actual or implied endorsement of such products by the U.S. Department of Health and Human Services.

\section{References}

1. T.H. Maiman, Nature 187, 493 (1960)

2. A. Javan, W.R. Bennett, D. Herriott, Phys. Rev. Lett. 6, 106 (1961)

3. L.F. Johnson, J. Appl. Physiol. 34, 897 (1961).

4. W.R. Bennett, W.L. Faust, R.A. McFarlane, C.K.N. Patel, Phys. Rev. Lett. 8, 470 (1962)

5. C.K.N. Patel, Phys. Rev. Lett. 13, 617 (1964).

6. R.W. Ryan, R.F. Spetzler, M.C. Preul, Neurosurg. Focus 27, E6 (2009).

7. H. Rose, D. Smart, Res. Rev. Clin. Trials 143 (1964).

8. K.M. Earle, S. Carpenter, U. Roessmann, M.A. Ross, J.R. Hayes, E. Zeitler, Fed. Proc. 24, 129 (1965).

9. M.M. Zaret, G.M. Breinin, I.M. Siegel, H. Ripps, H. Schmidt, Science 134, 1525 (1961)

10. L. Goldman, R.J. Rockwell, J. Am. Med. Assoc. 198, 641 (1966).

11. E. Klein, S. Fine, Y. Laor, M.S. Litwin, J. Donoghue, L. Simpson, J. Invest. Dermatol. 43, 565 (1964).

12. S. Stellar, T.G. Polanyi, J. Clin. Laser Med. Surg. 10, 399 (1992)

13. T.F. Deutsch, Phys. Today 41, 56 (1988).

14. S. Takac, S. Stojanović, B. Muhi, Med. Pregl. 51, 146 (1998).

15. G.S. Edwards, S.J. Allen, R.F. Haglund, R.J. Nemanich, B. Redlich, J.D. Simon, W.C. Yang, Photochem. Photobiol. 81, 711 (2005).

16. G. Edwards, R. Logan, M. Copeland, L. Reinisch, J. Davidson, B. Johnson, R. Maciunas, M. Mendenhall, R. Ossoff, J. Tribble, J. Werkhaven, D. O'Day, Nature 371, 416 (1994)

17. G. Edwards, R. Logan, M. Copeland, L. Reinisch, J. Davidson, B. Johnson, R. Maciunas, M. Mendenhall, R. Ossoff, J. Tribble, J. Werkhaven, D. O'Day, Proc. SPIE 2138, 35 (1994).

18. M.L. Copeland, R.J. Maciunas, G.S. Edwards, in Neurosurgical Topics: Advanced Techniques in Central Nervous System Metastases, R.J. Maciunas, Ed. (Thieme, NY, 1998), p. 113.

19. W. Sun, J.H. Shen, D.J. Shetlar, K.M. Joos, J. Glaucoma 9, 325 (2000).

20. S.H. Chung, E. Mazur, J. Biophotonics 2, 557 (2009).

21. A. Vogel, J. Noack, G. Huttman, G. Paltauf, Appl. Phys. B 81, 1015 (2005)

22. J.R. Bashford, Orthopaedics 16, 541 (1993).

23. T. Eliades, Am. J. Orthod. Dentofac. Orthop. 131, 253 (2007).

24. T.E. Gordon, D.L. Smith, J. Prosthet. Dent. 24, 472 (1970).

25. T. Yamagishi, M. Ito, Y. Fujimura, J. Prosthet. Dent. 70, 264 (1993)

26. G. Sjogren, M. Andersson, M. Bergman, Acta Odont. Scand. 46, 247 (1988).

27. C. Bertrand, Y. Le Petitcorps, L. Albingre, V. Dupuis, Br. Dent. J. 190, 255 (2001).

28. N. Amanat, N.L. James, D.R. McKenzie, Med. Eng. Phys. 7, 690 (2010).
29. A. Mian, G. Newaz, T. Mahmood, G. Auner, J. Mater. Sci. 42, 8150 (2007).

30. A. Mian, T. Sultana, D. Georgiev, R. Witte, H. Herfurth, G. Auner, G. Newaz, J. Biomed. Mater. Res. Part B 90B, 614 (2009).

31. T. Minamizato, J. Prosth. Dent. 63, 677 (1990).

32. B. Kasemo, J. Gold, Adv. Dent. Res. 13, 8 (1999).

33. F.A. Rueggeberg, Dent. Mater. 27, 39 (2011)

34. W.R. Lacefield, Implant Dent. 7,315 (1998).

35. A. Kurella, N.B. Dahotre, J. Biomater. Appl. 20,5 (2005).

36. J. Norton, K.R. Malik, J.A. Darr, I. Rehman, Adv. Appl. Ceram. 105, 113 (2006).

37. L.T. de Jonge, S.C.G. Leeuwenburgh, G.C. Wolke, G.C. Joop, J.A. Jansen, Pharm. Res. 25, 2357 (2008).

38. P.K. Chu, J.Y. Chen, L.P. Wang, N. Huang, Mater. Sci. Eng., R 36, 143 (2002) 39. I.N. Mihailescu, P. Torricelli, A. Bigi, I. Mayer, M. Iliescu, J. Werckmann, G. Socol, F. Miroiu, F. Cuisinier, R. Elkaim, G. Hildebrand, Appl. Surf. Sci. 248, 344 (2005).

40. M. Sygnatowicz, K. Keyshar, A. Tiwari, JOM 62, 65 (2010).

41. M. Jelinek, T. Kocourek, K. Jurek, J. Remsa, J. Miksovsky, M. Weiserova, J. Strnad, T. Luxbacher, Appl. Phys. A 101, 615 (2010).

42. W. Mroz, A. Bombalska, S. Burdynska, M. Jedynski, A. Prokopiuk, B. Budner, A. Slosarczyk, A. Zima, E. Menaszek, A. Scislowska-Czarnecka, K. Niedzielski, J. Mol. Struct. 977, 145 (2010)

43. A.C. Evans, J. Franks, P.J. Revell, Surf. Coat. Technol. 47, 662 (1991).

44. J. Franks, J. Vac. Sci. Technol., A 7, 2307 (1989).

45. J. Narayan, W.D. Fan, R.J. Narayan, P. Tiwari, H.H. Stadelmaier, Mater. Sci. Eng., B 25, 5 (1994).

46. M.L. Morrison, R.A. Buchanan, P.K. Liaw, C.J. Berry, R.L. Brigmon, L. Riester, H. Abernathy, C. Jin, R.J. Narayan, Diamond Relat. Mater 15, 138 (2006).

47. M. Jelinek, T. Kocourek, J. Remsa, R. Cristescu, I.N. Mihailescu, D.B. Chrisey, Laser Phys. 17, 66 (2007).

48. D.M. Bubb, B.R. Ringeisen, J.H. Callahan, M. Galicia, A. Vertes, J.S. Horwitz, R.A. McGill, E.J. Houser, P.K. Wu, A. Pique, D.B. Chrisey, Appl. Phys. A 73, 121 (2001).

49. R. Cristescu, C. Popescu, G. Socol, A. Visan, I.N. Mihailescu, S.D. Gittard, P.R. Miller, T.N. Martin, R.J. Narayan, A. Andronie, I. Stamatin, D.B. Chrisey, Appl. Surf. Sci. 257, 5287 (2011)

50. A. Malone, Scimed Life Systems Inc., Boston Sci. Ltd., International Application Number PCT/US2005/004596.

51. E. Gyorgy, I.N. Mihailescu, P. Serra, A. Perez del Pino, J.L. Morenza, Surf. Coat. Technol. 154, 63 (2002)

52. S.R. Paital, N.B. Narendra, Mater. Sci. Eng., R66, 1 (2009).

53. P.G. Engleman, A. Kurella, A. Samant, C.A. Blue, N.B. Dahotre, JOM 57, 46 (2005).

54. L.E. Murr, S.A. Quinones, S.M. Gaytan, M.I. Lopez, A. Rodela, E.Y. Martinez, D.H. Hernandez, E. Martinez, F. Medina, R.B. Wicker, J. Mech. Behav. Biomed. Mater. 2, 20 (2009)

55. S. Van Bael, B. Vandenbroucke, G. Kerckhofs, J. Schrooten, J.P. Kruth, Proc. TMS 2009 138th Annual Meeting \& Exhibition, Vol 1: Materials Processing and Properties, 333 (2009).

56. B. Vandenbroucke, J.P. Kruth, Rapid Prototyp. J. 13, 196 (2007).

57. Y.C. Hagedorn, J. Wilkes, W. Meiners, W. Konrad, R. Poprawe, Physics Procedia 5, 587 (2010)

58. A. Gebhardt, F.M. Schmidt, J.S. Hotter, W. Sokalla, P. Sokalla, Physics Procedia 5, 543 (2010).

59. I.V. Shishkovsky, L.T. Volova, M.V. Kuznetsov, Y.G. Morozov, I.P. Parkin, J. Mater. Chem. 18, 1309 (2008).

60. J.T. Rimell, P.M. Marquis, J. Biomed. Mater. Res. 53414 (2000).

61. I. Palcic, M. Balazic, M. Milfelner, B. Buchmeister, Mater. Manuf. Proc. 24 750 (2009).

62. G.D.J. Ram, C.K. Esplin, B.E. Stucker, J. Mater. Sci. - Mater. Med. 19, 2105 (2008).

63. B.K. Nayak, M.C. Gupta, Opt. Lasers Eng. 48, 940 (2010).

64. J.R. Bush, B.K. Nayak, L.S. Nair, M.C. Gupta, C.T. Laurencin, J. Biomed Mater. Res. Part B 97B, 299 (2011).

65. J.M. Rosen, M. Grosser, V.R. Hentz, Restor. Neurol. Neurosci. 2, 89 (1990). 66. C. Dupas-Bruzek, O. Robbe, A. Addad, S. Turrell, D. Derozier, Appl. Surf. Sci. 255, 8715 (2009).

67. C. Veraart, C. Raftopoulos, J.T. Mortimer, J. Delbeke, D. Pins, G. Michaux, A. Vanlierde, S. Parrini, M.-C. Wanet-Defalque, Brain Res. 813, 181 (1998) 68. S.P. Lacour, S. Wagner, R.J. Narayan, T. Li, Z.G. Suo, J. Appl. Phys. 100 $014913(2006)$

69. T.V. Chirila, I.J. Constable, P.P. Vansaarloos, G.D. Barrett, Biomaterials 11 305 (1990).

70. T.V. Chirila, G.D. Barrett, A.V. Russo, I.J. Constable, P.P. Vansaarloos, C.I. Russo, Biomaterials 11, 313 (1990).

71. T.J. Newland, M.L. McDermott, D. Eliott, L.D. Hazlett, D.J. Apple, R.J. Lambert, R.P. Barrett, J. Cataract Refract. Surg. 25, 72 (1999). 
72. K.P. Thompson, K. Hanna, G.O. Waring, I. Gipson, Y. Liu, R.P. Gailitis, B. Johnson-Wint, K. Green, Refract. Corn. Surg. 7, 240 (1991).

73. S.W. Robertson, V. Imbeni, H.R. Wenk, R.O. Ritchie, J. Biomed. Mater. Res. Part A 72A, 190 (2005).

74. S. Shabalovskaya, J. Anderegg, J. Van Humbeeck, Acta Biomater. 4, 447 (2008).

75. Z.D. Cui, H.C. Man, X.J. Yang, Surf. Coat. Technol. 192, 347 (2005).

76. Y.P. Kathuria, J. Mater. Process. Technol. 170, 545 (2005).

77. S.K. Sudheer, S. Prathibha, J. Micro/Nanolithogr. MEMS MOEMS 7, 033012 (2008).

78. S.K. Sudheer, V.P.M. Pillai, V.U. Nayar, Y. Pothiawala, D. Kothwala, J. Microlith. Microfab. Microsyst. 5, 023010 (2006).

79. D. Lootz, D. Behrend, S. Kramer, T. Freier, A. Haubold, G. Benkiesser, K.P. Schmitz, B. Becher, Biomaterials 22, 2447 (2001).

80. N. Grabow, M. Schlun, K. Sternberg, N. Hakansoon, S. Kramer, K.P. Schmitz, J. Biomech. Eng. Trans. ASME 127, 25 (2005).

81. N. Grabow, C.M. Buenger, C. Schultze, K. Schmohl, D.P. Marin, S.F. Williams, K. Sternberg, K.P. Schmitz, Ann. Biomed. Eng. 35, 2031 (2007).

82. M. Mielke, D. Gaudiosi, K. Kim, M. Greenberg, X. Gu, R. Cline, X. Peng, M. Slovick, N. Allen, M. Manning, M. Ferrel, N. Prachayaamorn, S. Sapers, J. Laser Micro/Nanoeng. 5, 53 (2010).

83. N. Muhammad, D. Whitehead, A. Boor, L. Li, J. Mater. Process. Technol. 210, 2261 (2010).

84. J.E. Sousa, M.A. Costa, A. Abizaid, A.S. Abizaid, F. Feres, I.M.F. Pinto, A.C. Seixas, R. Staico, L.A. Mattos, A.G.M.R. Sousa, R. Falotico, J. Jaeger, J.J. Popma, P.W. Serruys, Circulation 103, 192 (2001).

85. C. di Mario, H. Griffiths, M. Goktekin, N. Peeters, J. Verbist, M. Bosiers, K. DeLoose, B. Heublein, R. Rohde, B. Kasese, C. Ilsley, R. Erbel, J. Interv. Cardiol. 17, 391 (2004).

86. A. Tavakoli, M. Sohrabi, A. Kargari, Chem. Pap. 61, 151 (2007).

87. S. Veintemillas-Verdaguer, M.D. Morales, O. Bomati-Miguel, C. Bautista, X.Q. Zhao, P. Bonville, R.P. de Alejo, J. Ruiz-Cabello, M. Santos, F.J. TendilloCortijo, J. Ferreiros, J. Phys. D 37, 2054 (2004).

88. E. Popovici, F. Dumitrache, I. Morjan, R. Alexandrescu, V. Ciupina, G. Prodan, L. Vekas, D. Bica, O. Marinica, E. Vasile, Appl. Surf. Sci. 254, 1048 (2007).

89. T. Asahi, T. Sugiyama, H. Masuhara, Acc. Chem. Res. 41, 1790 (2008).

90. D.P. Singh, Sci. Adv. Mater. 2, 245 (2010).

91. T. Okada, B.H. Agung, Y. Nakata, Appl. Phys. A 79, 1417 (2004).

92. T. Okada, K. Kawashima, Y. Nakata, Thin Solid Films 506-507, 274 (2006).

93. T. Okada, J. Suehiro, Appl. Surf. Sci. 253, 7840 (2007).

94. K. Itoh, W. Watanabe, Y. Ozeki, Proc. IEEE 91, 1011 (2009).

95. E. Stratakis, A. Ranella, M. Farsari, C. Fotakis, Prog. Quantum Electron. 33 127 (2009)

96. R.J. Narayan, A. Doraiswamy, D.B. Chrisey, B.N. Chichkov, Mater. Today 13, $42(2010)$.

97. I. Sakellari, A. Gaidukeviciute, A. Giakoumaki, D. Gray, C. Fotakis, M. Farsari, M. Vamvakaki, C. Reinhardt, A. Ovsianikov, B.N. Chichkov, Appl. Phys. A 100, 359 (2010).

98. M. Farsari, B.N. Chichkov, Nat. Photonics 3, 450 (2009)

99. P.R. Miller, A. Ovsianikov, A. Koroleva, S.D. Gittard, B.N. Chichkov, R.J. Narayan, Am. Ceram. Soc. Bull. 90, 24 (2009).

100. R. Liska, M. Schuster, R. Inführ, C. Turecek, C. Fritscher, B. Seidl, V. Schmidt, L. Kuna, A. Haase, F. Varga, H. Lichtenegger, J. Stampfl, J. Coat. Technol. Res. 4, 505 (2007)

101. S. Maruo, K. Ikuta, H. Korogi, J. Microelectromech. Syst. 12, 533 (2003).

102. A. Koroleva, S. Schlie, E. Fadeeva, S.D. Gittard, A. Ovsianikov, J. Koch, R.J. Narayan, B. Chichkov, J. Opt. 12, 124009 (2010).

103. K.S. Lee, R.H. Kim, D.Y. Yang, S.H. Park, Prog. Polym. Sci. 33, 631 (2008).

104. C.N. LaFratta, T. Baldacchini, J.T. Fourkas, M.C. Teich, B.E.A. Saleh, M.J. Naughton, J. Phys. Chem. B 108, 11256 (2004).

105. A. Ovsianikov, B. Chichkov, 0. Adunka, H. Pillsbury, A. Doraiswamy, R.J. Narayan, Appl. Surf. Sci. 253, 6603 (2007).

106. C. Schizas, V. Melissinaki, A. Gaidukeviciute, C. Reinhardt, C. Ohrt, V. Dedoussis, B.N. Chichkov, C. Fotakis, M. Farsari, D. Karalekas, Int. J. Adv. Manuf. Technol. 48, 435 (2010).

107. A. Doraiswamy, C. Jin, R.J. Narayan, P. Mageswaran, P. Mente, R. Modi, R. Auyeung, D.B. Chrisey, A. Ovsianikov, B. Chichkov, Acta Biomater. 2, 267 (2006). 108. A. Ovsianikov, B. Chichkov, P. Mente, N.A. Monteiro-Riviere, A. Doraiswamy, R.J. Narayan, Int. J. Appl. Ceram. Technol. 4, 22 (2007).

109. S.D. Gittard, A. Ovsianikov, B.N. Chichkov, A. Doraiswamy, R.J. Narayan, Expert Opin. Drug Delivery 7, 1 (2010).

110. S.D. Gittard, P.R. Miller, R.D. Boehm, A. Ovsianikov, B.N. Chichkov, J. Heiser, J. Gordon, N.A. Monteiro-Riviere, R.J. Narayan, Faraday Discuss. 149, 171 (2011). 111. S.D. Gittard, A. Nguyen, K. Obata, A. Koroleva, R.J. Narayan, B.N. Chichkov, Biomed. Opt. Lett. 2, 3167 (2011).

112. W. Martanto, S.P. Davis, N.R. Holiday, J. Wang, H.S. Gill, M.R. Prausnitz, Pharm. Res. 21, 947 (2004).
113. H.S. Gill, M.R. Prausnitz, Pharm. Res. 24, 1369 (2007).

114. S.P. Davis, W. Martanto, M.G. Allen, M.R. Prausnitz, IEEE Trans. Biomed. Eng. 52, 909 (2005).

115. D.W. Bodhale, A. Nisar, N. Afzulpurkar, Microfluid. Nanofluid. 8, 373 (2010). 116. S.D. Gittard, R.J. Narayan, C. Jin, A. Ovsianikov, B.N. Chichkov, N.A. MonteiroRiviere, S. Stafslien, B. Chisholm, Biofabrication 1, 041001 (2009).

117. S.O. Choi, Y.C. Kim, J.H. Park, J. Hutcheson, H.S. Gill, Y.K. Yoon, M.R. Prausnitz, M.G. Allen, Biomed. Microdev. 12, 263 (2010).

118. J.R. Windmiller, G. Valdés-Ramirez, N. Zhou, M Zhou, P.R. Miller, C. Jin S.M. Brozik, R. Polsky, E. Katz, R. Narayan, J. Wang, Electroanal. 23, 2302 (2011) 119. R.F. Donnelly, R. Majithiya, T.R.R. Singh, D.I.J. Desmond, M.J. Garland, Y.K. Demir, K. Migalska, E. Ryan, D. Gillen, C.J. Scott, A.D. Woolfson, Pharm. Res. 28, 41 (2011).

120. S.H. Lee, H.H. Lee, S.S. Choi, Korean J. Chem. Eng. 28, 1913 (2011).

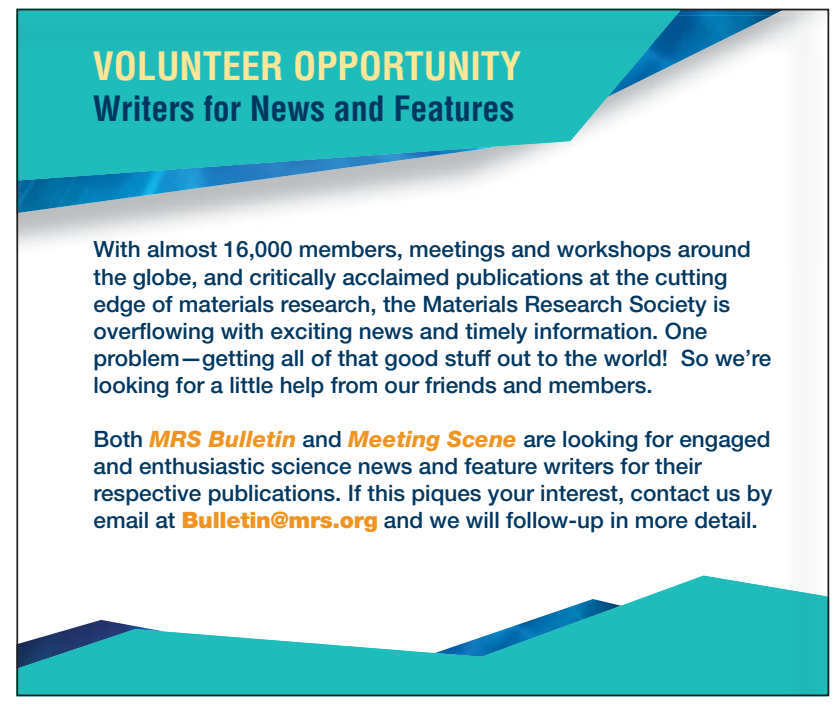

JA N I S

\section{Cryogenic Products for} Materials Characterization

Janis has a wide range of products geared towards the materials scientist, covering nearly any temperature range or application

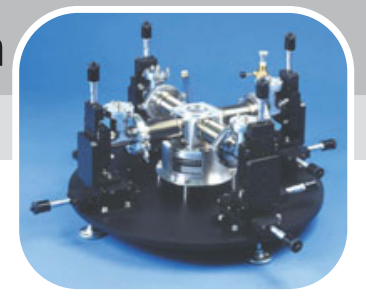

Typical techniques include: VSM, MOKE, FTIR, ESR, EPR, NMR, Hall effect, DLTS, Mössbauer, STM, AFM and more

Typical applications include:
- Microscopy

- UV-Vis-IR optical measurements

- Nanoscale electronics

- Spintronics

- High frequency measurements
- Non-destructive device and wafer testing

- Photovoltaics

- High Tc superconductors

- Terahertz detectors and devices 


\section{Thermo \\ S C I E N T I F I C}

\section{complete characterization}

Science continues to challenge the limits of material properties and capabilities. Whether improving conventional materials, such as tungsten alloys, or probing the potential of carbon fiber nanotechnology, our instruments and expertise help scientists characterize and confirm complex chemistries and unique structures. Our comprehensive offering includes innovative imaging and spectroscopy, industry-leading data management and proven method development. All designed to help provide deeper insights and more confident decisions as you drive bold progress in the materials of tomorrow.

\section{speeds discovery in materials science}

Nanotechnology

Polymers

Metallurgy

Microelectronics

Bio-Materials

Cement

Energy

Ceramics and Glass

Polymers

Carbon

Paints and Coatings

Chemicals

Paper and Printing

Medical Implants

Art Restoration 


\section{Make Every Electron Count ChemiSTEM $^{\text {TM }}$ Technology}

Introducing the newest member of the Titan family: Titan $^{\text {TM }}$ G2 80-200 with ChemiSTEM ${ }^{\text {TM }}$ Technology.

Combining FEl's groundbreaking ChemiSTEM Technology with Titan's market-leading sub-atomic resolution imaging, Titan G2 80-200 offers highly sensitive, fast elemental mapping, superior ultra-low concentration detection and the highest analytical probe current available. Even EDX tomography is easily achieved with stunning results.

GaAs Atomic EDX showing 1.4 Angstroms dumbbells with Titan G2 80-200 with ChemiSTEM Technology

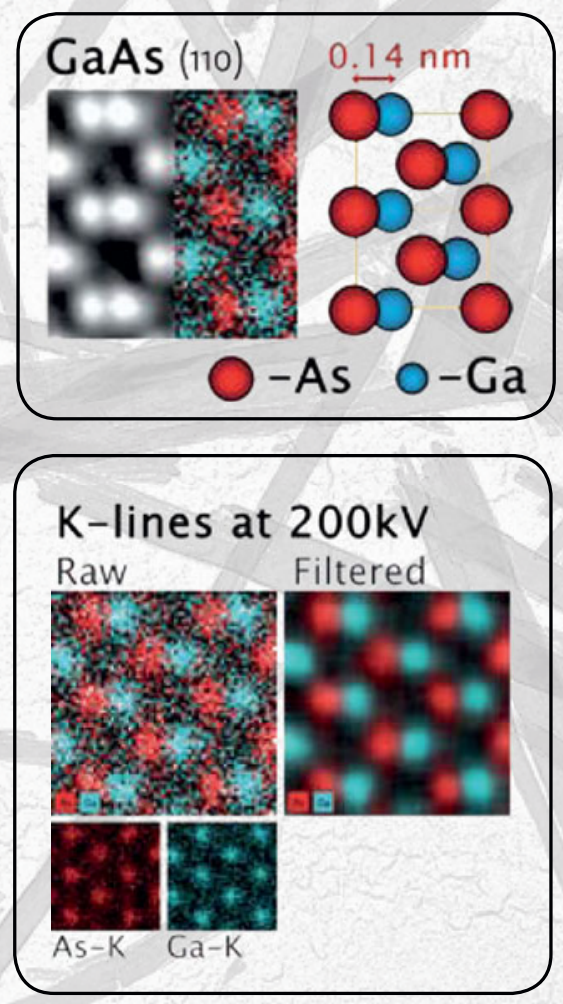

$\mathrm{La}_{1-\mathrm{x}} \mathrm{Sr}_{\mathrm{x}} \mathrm{MnO}_{3} / \mathrm{SrRuO}_{3}$ multilayer/quantum well systems in [100] projection

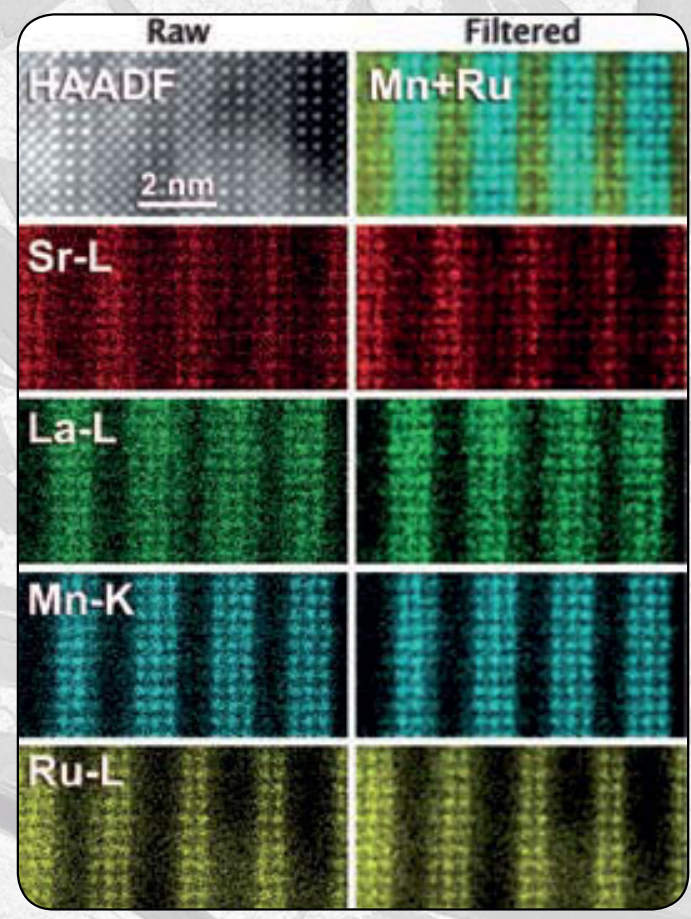

Sample courtesy of lonela Vrejoiu and Eckhard Pippel, Max Planck Institute of Microstructure Physics, Halle/Saale, Germany. 